\title{
Effect evaluation of the boom length and the bucket capacity of a dragline on its weight
}

\author{
A.A. Khoreshok \\ Dr.Sc., Professor, Department of Mining Machines and Complexes, T.F. Gorbachev Kuzbass State Tech- \\ nical University, Mining Institute
}

M.A. Tyulenev

MSc, PhD, Professor, Department of Open Pit Mining, T.F. Gorbachev Kuzbass State Technical University, Mining Institute

S.O. Markov

MSc, PhD, Associate Professor, Department of Surveying and Geology, T.F. Gorbachev Kuzbass State Technical University, Mining Institute

M. Cehlár

Dr.h.c. prof. Ing., Faculty of Mining, Ecology, Process Control and Geotechnologies, Technical University of Kosice

\section{J. Janočko}

Prof. Ing., CSc., Dr. scient., Faculty of Mining, Ecology, Process Control and Geotechnologies, Technical University of Kosice

\begin{abstract}
One of the most important components of a dragline excavator is a boom. The weight of the boom has a significant impact on the weight of the entire machine, despite the fact that its weight is only $4.5-6.5 \%$ of the weight of the entire machine. High weight of the boom increases the weights of the mast, A-frame, revolving frame, etc. All this leads to increased specific ground pressure, which in turn leads to the need to increase the supporting surfaces of the excavator. The moment of inertia of the boom is $30-40 \%$ in the overall balance of the moment of inertia, and therefore significantly affects the power of the rotary mechanism and the duration of the cycle of the excavator, and the tilting moment from the weight of the boom is close to the tilting moment from the weight of the bucket with the rock.

When the weight of the boom is reduced, it is possible to increase the capacity of the bucket or the length of the boom without increasing the weight of the excavator, and these indicators are known to be the main parameters of the dragline. For example, it happened with an ESH 14.75 excavator. The initial parameters of the machine (serial numbers 1 and 2) are 14.65 (bucket capacity is $14 \mathrm{~m}^{3}$, boom length is 65 meters) then 10.75 (serial numbers $3,4,5$ ) and 14.75 (serial numbers from 6 to 28) and ESH 20.65 (serial number 11). Now the factory produces an excavator ESH 15.90. The weight of the excavator has remained unchanged and makes up 1400 tons. Other main components of the excavator (tub, revolving frame, mechanisms) have not undergone significant changes.
\end{abstract}

\section{INTRODUCTION}

There is no consensus on whether the main parameter of a dragline - bucket capacity or boom length - is prevalent. On the one hand, the main idea of the transportless technology implies that the excavator should provide maximum distance for rock removing, and on the other 
hand, minimizing the volume of soil handled in one work cycle of excavator leads to a sharp decrease in the technical performance of the company (Bereznyak et al, 1970; Demirel, 2011; Huddart and Runge, 1979; Nazarov, 2011; Palamarchuk et al, 2019; Sadri and Lee, 1982; Scott et al, 2010; Seib and Carr, 1990). At this paper attempts to assess the impact of the length of the dragline's boom and the bucket capacity on the weight of the machine as a whole, since it is the weight of the excavator that characterizes the metal capacity of machinery.

Optimization of the main parameters of the dragline - bucket capacity and boom length should not lead to a significant increase in the weight of the excavator, as increasing the specific metal capacity of the machine will lead to changes in other technological parameters, changes in the geomechanical conditions of the application of the excavator and changes the parameters of internal dumping technology. In particular, the working cycle time of the excavator will be increased (Poderni, 2001; Markov et al., 2019; Katsubin and Fedotov, 2019; Dubinkin et al., 2019; Strelnikov, 2019), the limit height and angles of slopes of the overburden bench and dump's tiers will be reduced, which will lead to a decrease in the productivity of the excavator and reduce the capacity of internal dumps.

In order to maintain the technological parameters at an optimal level, it is necessary to maintain an optimal ratio between the length of the boom, bucket capacity and the specific metal capacity of draglines working on the internal dumping (Demirel and Frimpong, 2009; Elliott, 1989; Lee, 1988; Michaud and Calder, 1988; Runge, 1983; Ramani and Bandopadhyay, 1985; Soloviev and Kuziev, 2017; Sengstock, 1992; Townson et al, 2003).

\section{MATERIALS AND METHODS}

The weight of a dragline and the weight of its main components, including the boom, all other things being equal, depend on two main factors: the capacity (or weight) of the bucket with soil (rock) and the maximum bucket outreach with soil - the operating parameters of the excavator. Obviously, the latter depends on the length of the excavator boom $L$.

Since the boom angle of powerful excavators is usually equal to $30^{\circ}$, then the bucket outreach $L_{b o}$ is proportional to the length of the boom and usually numerically equal to this length, i.e.

$$
L_{b o}=a+L \cdot \cos \alpha \cong L
$$

where $L_{b o}$ is the bucket outreach, $\mathrm{m} ; a$ is the distance from the excavator's axis of rotation to the boom foot, $\mathrm{m} ; L$ is the boom length, $\mathrm{m} ; \alpha$ is the angle of the boom, degree $\left(\alpha=30^{\circ}\right)$.

However, apart from these two main factors, the excavator weight is also significantly influenced by its design, which is determined by the success and modernity of solutions of its individual components, as well as the correct choice of design and calculation schemes, determining the design loads, calculation methods and reserves of strength, structural materials, etc.

The main indicator used for comparison of draglines is the ratio of excavator weight to the product of bucket capacity into boom length, it is also used when comparing the weight of excavator booms.

$$
W_{e}=k \cdot B \cdot L,
$$

where $k$ - excavator (or excavator boom) weight factor, $\mathrm{t} /\left(\mathrm{m}^{3} \cdot \mathrm{m}\right) ; W_{e}$ - excavator weight, $\mathrm{t} ; B$ excavator bucket capacity, $\mathrm{m}^{3} ; L$ - boom length, $\mathrm{m}$.

The graph of dependence $W_{e}=f(B, L)$ is constructed by Ing. V.V. Rudoiskatel (Figure 1). In this case, it is assumed that the weight of the bucket with soil - the end load allowed at the 


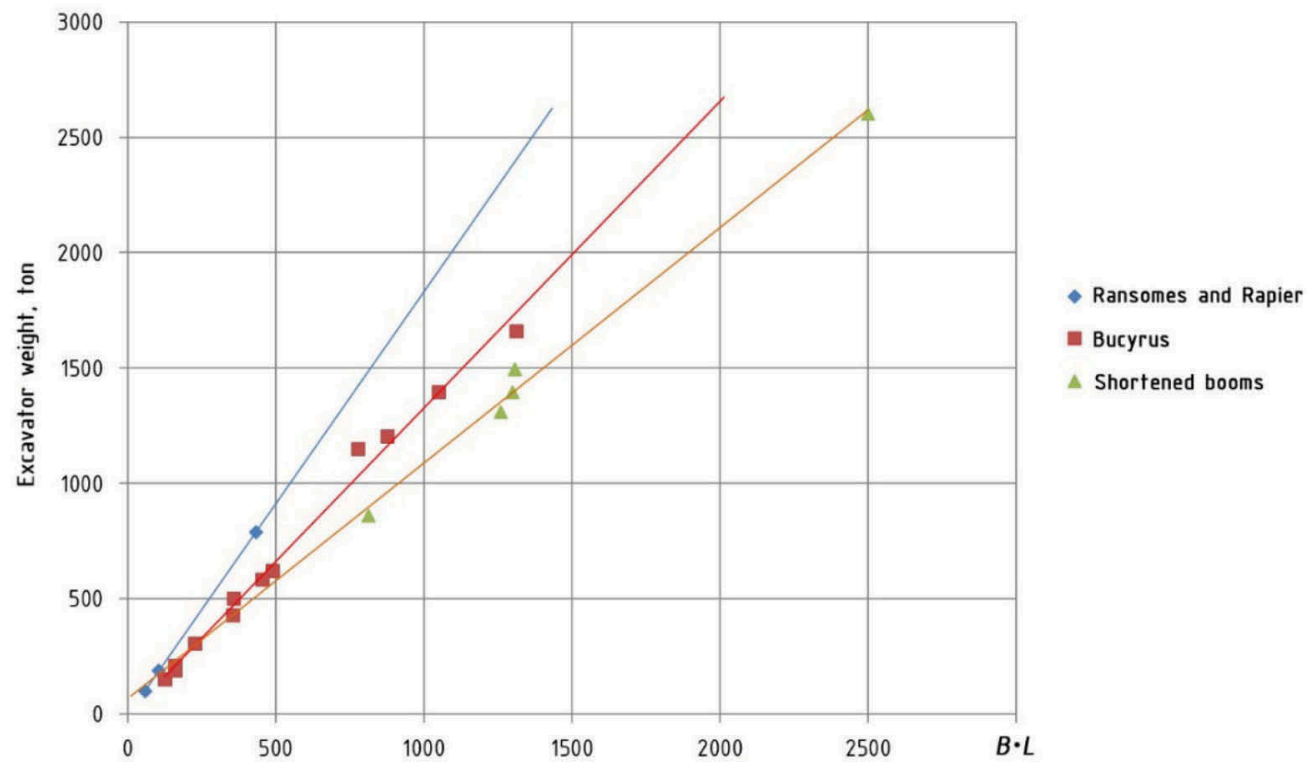

Figure 1. Plots of dependence of excavator weight on the product bucket capacity per boom length.

end of the boom - is proportional to the capacity of the bucket. In fact, the weight of $1 \mathrm{~m}^{3}$ of bucket capacity with soil $-\gamma_{\mathrm{b}+\mathrm{s}}$ of most excavators ranges from 2.9 to $3.2 \mathrm{t} / \mathrm{m}^{3}$. Given this spread, it would be more accurate in the formula (2) instead of the bucket capacity to apply the weight of the bucket with soil (end load $W_{b+s}$ ), or corresponding to this load capacity of the bucket with soil at a standard value of the specific weight of the bucket with soil, for example, $\gamma_{\mathrm{b}+\mathrm{s}}=3.2 \mathrm{t} / \mathrm{m}^{3}$. But even in this form, the formula can accurately reflect the weight of the excavator (and the excavator boom) only at certain ratios of bucket weight and boom length.

A similar relationship is recommended by Bucyrus-Erie engineer Henry Rumfelt.

$$
W_{e}=W \cdot r
$$

where $W_{e}$ is the weight of the excavator, tons; $W$ is the weight of the filled bucket, tons; $r$ is the arm of the highest load, $\mathrm{m}$.

The weight of the filled bucket is taken at the rate of 4750 pounds per cubic yard of bucket nominal size ( 2.8 tons per $1 \mathrm{~m}^{3}$ of bucket nominal capacity). Rumfelt's load radius is as follows: it determines the diameter of the tub based on an average specific pressure of $0.71 \mathrm{~kg} /$ $\mathrm{cm}^{2}$ and a safe distance from the nearest slope, which is assumed to be $1.525 \mathrm{~m}$ ( 5 feet). From the obtained point the distance $r$ to the bucket unloading point is determined. The obtained ratio is characterized by a straight line, having a tangent angle of 1:575 for existing models of excavators and a straight line having tangent angle of 1:467 for the designed models.

K.N. Trubetskoy and K.E. Vinitsky (Trubetskoy et al., 1994) determine the weight of the excavator depending on the value of the tilting moment by expression:

$$
W_{e}=80 \cdot M_{q}^{0.419}-934
$$

where $M_{q}=B \cdot L \cdot \cos \alpha \cdot\left(g_{q}+\gamma\right), t \cdot m, M_{q}=W_{b+s} \cdot L \cdot \cos \alpha$.

This formula does not take into account the design of excavators and is only correct for some sizes of draglines. 
The lack of these dependencies can be easily identified when considering the weighting coefficients of different modifications of the same excavator. For example, a Marion 7800 excavator has a weight factor $k$ that varies from $1.1 \mathrm{t} / \mathrm{m}^{3} \cdot \mathrm{m}$ (for a bucket with a capacity of $15.3 \mathrm{~m}^{3}$ and an $85.3 \mathrm{~m}$ long boom) to $0.81 \mathrm{t} / \mathrm{m}^{3} \cdot \mathrm{m}$ (for a bucket with a capacity of $26.7 \mathrm{~m}^{3}$ and a $67.1 \mathrm{~m}$ long boom), i.e. with a $75 \%$ increase in bucket capacity, the length of the boom is reduced by only $27 \%$. Hence the lower weight factor value for excavators with shortened booms.

Similarly for ESH 14/75 and ESH 20/65 excavators with the same design and all other equal conditions the construction coefficient for ESH 14/75 is $k=1.33$, and for ESH 20/65 - 1.075, i.e. $24 \%$ lower.

From these examples it can be seen that reducing the length of the boom allows increasing the capacity of the bucket by a much higher value, therefore, the length of the boom affects the weight of the excavator and its structure to a greater extent than the capacity of the bucket.

Below are the main dependencies for determining the weight of excavators and excavator booms on the operating parameters of the excavator (bucket capacity and length of the boom), as well as the impact of reducing the weight of the boom and the weight of the bucket on the weight of the entire excavator.

\section{DEPENDENCE OF EXCAVATOR WEIGHT ON OPERATING PARAMETERS}

The weight of an excavator depends on the capacity of its bucket and the length of the boom, because the value of these two parameters depends on the load on the construction of the excavator. If we express the excavator weight $W_{e}$ as a degree dependence on the capacity of the bucket $B$ and the length of the boom $L$, ie

$$
W_{e}=k \cdot B^{\alpha} \cdot L^{\beta}
$$

then the values $k, \alpha, \beta$ can be obtained from the available range of excavators. Then (4) will have the following form:

$$
W_{e}=k_{1} \cdot B^{0.65} \cdot L^{1.65}=k_{1} \cdot A
$$

where $k_{1}$ is the ratio of proportionality depending on the design of the excavator, $A$ is the ratio depending on bucket capacity and boom length.

Table 1 shows the values of $k_{1}$ for draglines of different manufacturers and defines the values of excavator weights calculated by (6) and actual excavator weights; the difference in weights almost everywhere does not exceed $5 \%$.

When using all the dependencies, including the values of $B$ and $L$, it is necessary to bring the bucket capacity to the equivalent weight, i.e. take the weight of the bucket with a soil $3.2 \mathrm{t} / \mathrm{m}^{3}$, and the boom length - to the equivalent length, at an angle of slope of $30^{\circ}$. The table shows that the Ransomes \& Rapier W600 excavator is the heaviest one. The lightest are excavators of Uralmash plant ESH $15 / 90$ and ESH 25/100, for which the value of coefficient $k_{1}=0,147$. For each company the value of coefficient $k_{1}$ is the constant value. Figure 2 shows a nomogram to determine the value of $A$, which is necessary to calculate the weight of an excavator by formula (6). Values of coefficient $k_{1}$ for excavators of different manufacturers are given in Table 2.

The verification of formula (6) according to some models of excavators Ransomes \& Rapier shows that at $k_{1}=0.159$ weights of all modifications of excavator W1880 and W1350 accurately confirm the obtained formula (see Table 1).

Thus, the possibility of changing certain parameters of modular (dynamic) elements within one dragline model is determined by their design features. 
Table 1. Theoretical and calculated by formula (6) excavator weights.

\begin{tabular}{|c|c|c|c|c|c|c|c|}
\hline \multirow[b]{2}{*}{ Manufacturer } & \multirow[b]{2}{*}{ Model } & \multirow[b]{2}{*}{$B, \mathrm{~m}^{3}$} & \multirow[b]{2}{*}{$L, \mathrm{~m}$} & \multirow[b]{2}{*}{$k_{1}$} & \multicolumn{2}{|c|}{ Excavator weight, ton } & \multirow{2}{*}{$\begin{array}{l}\text { Weight deviation } \\
\Delta, \%\end{array}$} \\
\hline & & & & & theoretical & calculated & \\
\hline \multirow{10}{*}{ Marion } & \multirow[t]{4}{*}{ M7800 } & 15.0 & 85.3 & 0.162 & 1460 & 1464 & 0.3 \\
\hline & & 19.0 & 79.0 & 0.162 & 1460 & 1490 & 2.0 \\
\hline & & 23.0 & 73.0 & 0.162 & 1460 & 1476 & 1.1 \\
\hline & & 27.0 & 67.0 & 0.162 & 1425 & 1415 & -0.7 \\
\hline & \multirow[t]{3}{*}{ M7400 } & 5.4 & 71.6 & 0.162 & 550 & 554 & 0.7 \\
\hline & & 6.9 & 67.0 & 0.162 & 585 & 586 & 0.1 \\
\hline & & 8.4 & 61.0 & 0.162 & 585 & 570 & -2.6 \\
\hline & \multirow[t]{2}{*}{ M7200 } & 4.6 & 41.1 & 0.162 & 196 & 201 & 2.5 \\
\hline & & 5.4 & 36.6 & 0.162 & 196 & 184 & -6.4 \\
\hline & $950 \mathrm{~B}$ & 13.0 & 64.0 & 0.205 & 990 & 1038 & 4.6 \\
\hline \multirow{4}{*}{ Bucyrus } & $1250 \mathrm{~B}$ & 17.6 & 67.6 & 0.205 & 1290 & 1383 & 6.7 \\
\hline & $1250 \mathrm{~B}$ & 23.0 & 58.7 & 0.205 & 1330 & 1304 & -2.0 \\
\hline & 500 & 6.1 & 61.8 & 0.205 & 595 & 599 & 0.7 \\
\hline & 500 & 7.65 & 56.4 & 0.205 & 605 & 597 & -1.4 \\
\hline \multirow{10}{*}{ Ransomes \& Rapier } & 200 & 3.1 & 41.1 & 0.205 & 195 & 197 & 0.9 \\
\hline & 1400 & 15.3 & 86.0 & 0.189 & 1740 & 1732 & -0.5 \\
\hline & 150 & 3.1 & 40.2 & 0.189 & 174 & 175 & 0.5 \\
\hline & 600 & 6.1 & 61.5 & 0.277 & 800 & 803 & 0.3 \\
\hline & 600 & 7.65 & 56.0 & 0.277 & 800 & 797 & -0.4 \\
\hline & 600 & 9.2 & 50.0 & 0.277 & 750 & 745 & -0.7 \\
\hline & 1800 & 18.3 & 92.3 & 0.159 & 1880 & 1839 & -2.2 \\
\hline & 1800 & 22.9 & 85.9 & 0.159 & 1880 & 1890 & 0.5 \\
\hline & 1800 & 30.6 & 75.5 & 0.159 & 1880 & 1844 & -2.0 \\
\hline & 1350 & 15.3 & 82.0 & 0.159 & 1350 & 1347 & -0.3 \\
\hline \multirow{4}{*}{ Uralmash } & $14 / 75$ & 14.0 & 75.0 & 0.203 & 1400 & 1401 & 0.0 \\
\hline & $20 / 65$ & 20.0 & 65.0 & 0.203 & 1400 & 1395 & -0.4 \\
\hline & $15 / 90$ & 15.0 & 90.0 & 0.147 & 1430 & 1433 & 0.2 \\
\hline & $25 / 100$ & 25.0 & 100.0 & 0.147 & 2420 & 2377 & -1.8 \\
\hline
\end{tabular}

\section{EFFECT OF BUCKET WEIGHT REDUCTION ON EXCAVATOR WEIGHT}

It is important to lighten the weight of the bucket to reduce the excavator weight. By saving the bucket weight, you can increase its volume or reduce the excavator weight. Let's consider how the excavator weight changes when the bucket weight changes.

The weight $W$ of the bucket with the capacity $B$ with the soil having density $\gamma_{s}$ can be presented in the form:

$$
W=B \cdot\left(\gamma_{b}+\gamma_{s}\right),
$$

where $\gamma_{b}, \gamma_{s}-$ specific weights of bucket and soil, respectively.

At reduction of weight of a bucket design in $n$ times and corresponding increase in bucket capacity, weight of a bucket with soil will be

$$
W_{1}=B_{1} \cdot\left(n \cdot \gamma_{b}+\gamma_{s}\right)
$$

With the constant weight of the bucket with the soil

$$
\begin{gathered}
W=W_{1}, \\
B_{1}=\frac{B \cdot\left(\gamma_{b}+\gamma_{s}\right)}{n \cdot \gamma_{b}+\gamma_{s}} .
\end{gathered}
$$




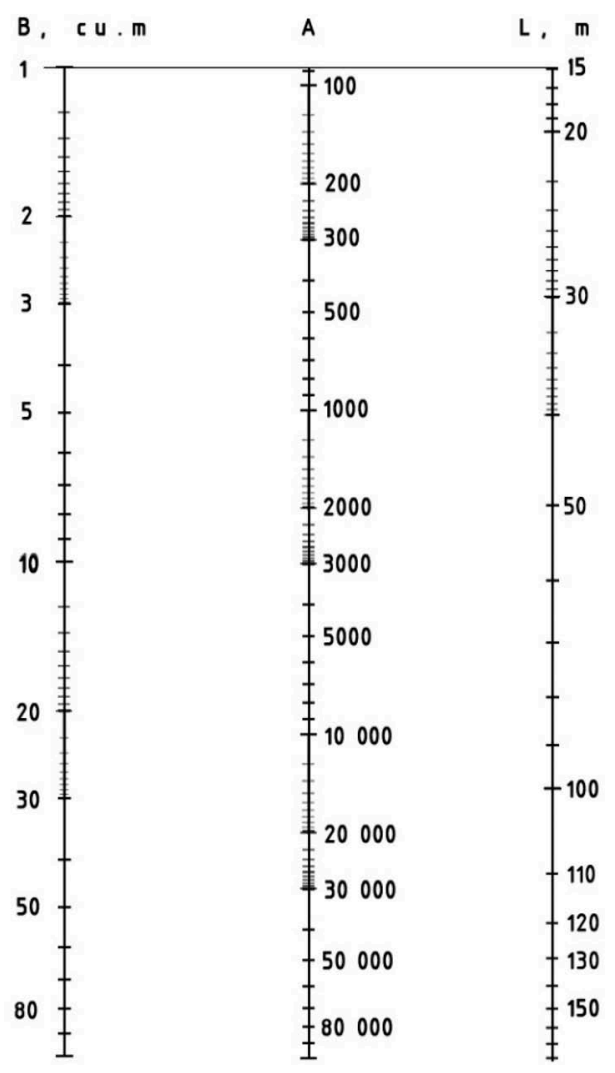

Figure 2. Nomogram for determining $A$ value.

Table 2. Values of coefficient $k_{1}$ and $k_{1}^{\prime}$ for excavators of different manufacturers.

\begin{tabular}{llll}
\hline Manufacturer, model & $k_{1}$ & $k_{1}^{\prime}$ & Boom construction \\
\hline Marion & 0.162 & - & \\
Bucyrus & 0.205 & - & \\
Ransomes \& Rapier & 0.189 & 0.011 & Rigid triple lattice \\
Ransomes \& Rapier 600 & 0.277 & - & Rigid triple lattice \\
Ransomes \& Rapier 1800 & 0.159 & - & Rigid triple lattice \\
ESH 6/60 & 0.208 & 0.0115 & Rigid triple lattice \\
ESH 14/75 & 0.203 & 0.0096 & Cable \\
ESH15/90, ESH 25/100 & 0.147 & 0.008 & Cable advanced \\
\hline
\end{tabular}

Using formula (6) we will find the ratio of excavator weights with buckets of capacity $B$ and $B_{1}$ :

$$
\frac{W_{1}}{W}=\frac{k \cdot B_{1}^{0.65} \cdot L^{1.65}}{k \cdot B^{0.65} \cdot L^{1.65}} \text { or } W_{1}=W \cdot\left(\frac{B_{1}}{B}\right)^{0.65}
$$

Reducing the specific weight of the bucket of an ESH 25/100 excavator by $20 \%$, which is 8 tons with the bucket weight of 40 tons, will reduce the excavator weight by $4 \%$, which is 100 tons. 


\section{EFFECT OF BOOM WEIGHT REDUCTION ON EXCAVATOR WEIGHT}

The weight of the draglines' booms also depends on the above factors (bucket capacity, length of the boom) and can be expressed as the same formula (5) as the weight of the dragline:

$$
W_{\text {boom }}=k_{1}^{\prime} \cdot B^{0.65} \cdot L^{1.65}=k_{1}^{\prime} \cdot A
$$

where $k_{1}^{\prime}$ is a coefficient depending on excavator boom's design.

Table 3 shows the actual weights of the booms and the weights of the same booms determined by the formula (11).

The difference between the theoretical and actual weight does not exceed $1.5 \%$. Thus, the nomogram shown in the Figure 2 can be used to determine the weight of the booms. The load on the excavator boom suspension, and therefore on all other structures, is characterized by the tilting moment relative to the heel of the boom from the weight of the boom and the weight of the bucket with the soil:

$$
M_{\text {tilt }}=W_{\text {boom }} \cdot l_{b f}+W_{\text {bucket }} \cdot l_{b b}
$$

where $l_{b f}, l_{b b}$ - distances from boom foot to mass center of boom and bucket, respectively. Usually, mass center of the boom is located approximately in its middle, i.e.

$$
l_{b f} \approx 0.5 l_{\text {boom }}
$$

Therefore, with respect to the loads on the structures, a decrease in boom weight by $\Delta W_{\text {boom }}$ is equivalent to a decrease in bucket weight by $0.5 \Delta W_{\text {bucket }}$. Thus, the weight reduction of the boom by $\eta$ percent

$$
\Delta W_{\text {boom }}=\frac{\eta \cdot k_{1} \cdot A}{100}
$$

is equal to bucket weight reduction by

$$
\Delta W_{\text {bucket }}=0.5 \cdot \Delta W_{\text {boom }}=\frac{0.5 \cdot \eta \cdot k_{1} \cdot A}{100}
$$

\begin{tabular}{|c|c|c|c|c|c|c|}
\hline \multirow[b]{2}{*}{ Dragline model } & \multirow[b]{2}{*}{$B, \mathrm{~m}^{3}$} & \multirow[b]{2}{*}{$L, \mathrm{~m}$} & \multirow[b]{2}{*}{$k_{1}^{\prime}$} & \multicolumn{2}{|c|}{ Boom weight, ton } & \multirow[b]{2}{*}{ Weight deviation $\Delta, \%$} \\
\hline & & & & actual & theoretical & \\
\hline \multicolumn{7}{|c|}{ Cable boom } \\
\hline ESH 14/75 & 14.0 & 75.0 & 0.00945 & 65.5 & 65.0 & -0.5 \\
\hline ESH 20/65 & 20.0 & 65.0 & 0.00945 & 64.5 & 65.0 & 0.7 \\
\hline \multicolumn{7}{|c|}{ Cable advanced boom } \\
\hline ESH 15/90 & 15.0 & 90.0 & 0.008 & 77.0 & 78.0 & 1.3 \\
\hline ESH $25 / 100$ & 25.0 & 100.0 & 0.008 & 130.0 & 129.0 & -0.5 \\
\hline
\end{tabular}

or reduction of the bucket capacity by

$$
\Delta B=\frac{0.5 \cdot \eta \cdot k_{1} \cdot A}{100 \cdot \gamma_{b+s}} .
$$

Table 3. Comparison of actual excavator boom weights with weights calculated by formula (11). 
Weight of the excavator having bucket of capacity equal to $B_{1}=B-\Delta B$ is

$$
W_{e}^{\prime}=k \cdot A^{\prime}=k \cdot(B-\Delta B)^{0.65} \cdot L^{1.65} .
$$

The weight reduction of the excavator $\beta$ as a percentage will be as follows

$$
\beta=\frac{W_{e}-W_{e}^{\prime}}{W_{e}} \cdot 100=\left(1-\left(\frac{B-\Delta B}{B}\right)^{0.65}\right) \cdot 100=\left(1-\left(1-\frac{0.5 \cdot \eta \cdot k_{1} \cdot L^{1.65}}{B^{0.35} \cdot 100 \cdot \gamma}\right)\right) \cdot 100
$$

If we take the weight of 1 cubic meter of bucket with soil as $\gamma_{\mathrm{b}+\mathrm{s}}=3.2 \mathrm{t} / \mathrm{m}^{3}$, and the coefficient $k_{1}$ for cable booms can be taken as 0.008 , the final expression for $\beta$ will look like:

$$
\beta=\left(1-\left(1-125 \cdot 10^{-7} \cdot \eta \cdot \frac{L^{1.65}}{B^{0.35}}\right)\right) \cdot 100 .
$$

With different $L$ and $B$ we get:

\begin{tabular}{lll}
\hline$L, \mathrm{~m}$ & $B, \mathrm{~m}^{3}$ & $\beta$ \\
75 & $10<B<25$ & $0,35-0,45$ \\
100 & $25<B<50$ & $0,4-0,5$ \\
125 & $25<B<75$ & $0,6-0,7$ \\
\hline
\end{tabular}

Smaller coefficients correspond to larger bucket capacities.

\section{CONCLUSIONS}

The average coefficient value $\beta=0.5 \eta$ shows that a $1 \%$ reduction in the weight of the boom results in a $0.5 \%$ reduction in the weight of the excavator. The weight reduction of ESH $25 /$ 100 boom by $10 \%$ (15 t) will reduce the weight of the excavator by approximately $5 \%(120 \mathrm{t})$.

Reducing the specific weight of the bucket of an ESH 25/100 excavator by $10 \%$, which is 4 tons with the bucket weight of 40 tons, will reduce the excavator weight by $2 \%$, which is 50 tons.

Similarly, the increase in excavator weight will change as the boom and bucket weight increases. Available geomechanical parameters of both natural rock massif and blasted-andmoved rock mass (the tensile and shear strength, internal friction angle, watercut) should ensure placement of the excavator with the maximum possible boom length and bucket capacity. This condition is necessary to achieve optimal performance of the mining enterprise in specific mining and geological conditions.

In other words, a dragline that is planned to be implemented in a particular mining and geological environment must meet its characteristics.

\section{REFERENCES}

Bereznyak, M.M., Kalinin A.V. \& Pronoza, V.G. 1970. A method of calculating the width of the caved rubble in the transportless system of working a series of sloping beds. Soviet Mining 6(6):638-643.

Demirel, N. \& Frimpong, S. 2009. Dragline dynamic modelling for efficient excavation. International Journal of Mining, Reclamation and Environment 23(1): 4-20.

Demirel, N. 2011. Effects of the rock mass parameters on the dragline excavation performance. Journal of Mining Science 47(4): 441-449.

Dubinkin, D.M., Sadovets, V.Yu., Kotiev, G.O. \& Kartashov, A.V. 2019. Overburden and coal transportation research at open pit mines. Journal of Mining and Geotechnical Engineering 4(7): 50-66. 
Elliott, M.J. 1989. <i>Multiple Seam Stripping at Navajo Mine, Draglines - Operation, Maintenance and Control</i>. ACIRL Proceedings, Monograph OLD.

Huddart, H. \& I. Runge. 1979. Pit design optimised for dragline productivity. Transactions of Institute of Mining and Metallurgy. 88: A6-A12.

Katsubin, A.V. \& Fedotov, A.A. 2019. Systematization of the mining and geological conditions of the coal-bearing and coal-free zones of the Kuzbass open pits. Journal of Mining and Geotechnical Engineering 3(6): 60-75.

Lee, C.D. 1988. A multi-seam dragline mine planning simulator for personal computers. In Singhal (ed.), Mine Planning and Equipment Selection: 397-408. Rotterdam: Balkema.

Markov, S., Janocko, J., Tyulenev, M. \& Litvin, Y. 2019. Perspectives for the Transportless Mining Technology in Siberia and Far East Coal Deposits. E3S Web of Conferences 105: 01021.

Michaud, L.H. \& P. Calder, 1988. Computerised dragline mine planning. In Fytas, Collins \& Singhal (eds.), Computer Applications in the Mineral Industry: 353-357. Rotterdam: Balkema.

Nazarov, I.V. 2011. Numerical modeling of overburden rehandling with draglines. Journal of Mining Science 48(1): 55-61.

Palamarchuk, A.B., Stukan, A.V. \& Gvozdkova, T.N. 2019. Using of transportless technology during «VI» coal seam mining on Tomusinsky open pit mine. Journal of Mining and Geotechnical Engineering 1(4): 50-68.

Poderni, R.Yu. Mechanical equipment of open pits. 2001. Moscow: Mining Media Group.

Ramani, R.V. \& S. Bandopadhyay. 1985. A computer simulation model for surface mine reclamation planning. Bureau of Mines. United States Department of the Interior.

Runge, I.C. 1983. The design of multi-seam open pit coal mines a step by step case study. Proceeding of the First Conference on Use of Computers in the Coal Industry: 145-155. New York: Society of Mining Engineers, AIME.

Sadri, J.R. \& C. Lee. 1982. Optimization of single and multiple seam dragline mines through simulation. In Johnson and Barnes (eds.), 17th International Symposium on the Application of Computers and Operations Research in the Mineral Industry: 642-654. New York: Society of Mining Engineers, AIME.

Seib, W \& Carr, G. 1990. Maximum coal recovery using a dragline at Callide mine. Open Cut Mining Coal Marketing \& Mine Planning: 1-13. ACIRL, Coal Research \& Consultants, Seminar Proceedings. Singleton, NSW.

Sengstock, G.W. 1992. Blast profile control for dragline productivity optimization. Proceeding of the Third Large Open Pit Mining Conference: 269-274. Melbourne: The Australasian Institute of Mining and Metallurgy.

Soloviev, S. \& Kuziev, D. 2017. Dragline ESH-10/70 linkage stiffness parameters study. Ugol' 1(1090): $37-38$.

Strelnikov, A.V. 2019. Typical faces passports for the development of coal-bearing zones of Kuzbass quarry fields with backhoes. Part 1. General provisions. Journal of Mining and Geotechnical Engineering 3(6): 4-20.

Townson, P. G., Murthy, D. N.P. \& Gurgenci, H. 2003. Optimization of dragline load, in Case Studies in Reliability and Maintenance. In Blischke, W.R. \& Prabhakar Murthy, D.N. (eds.), Wiley Series in Probability and Statistics: 517-544. New Jersey, USA: Wiley.

Trubetskoy, K.N., Potapov, M.G., Vinitskiy, K.E. \& Melnikov N.N. (eds.). 1994. Open pit mines: guidebook. Moscow: Mine Bureau. 